\title{
A inflexão dos Direitos Humanos na Política de Saúde Mental e Drogas
}

\author{
The bending of Human Rights in Drugs and Mental Health Policy
}

Rosiane Oliveira da COSTA*

https://orcid.org/000o-0001-8956-095X

\author{
Nívea Maria Santos Souto MAIOR** \\ https://orcid.org/oooo-0003-4561-8819
}

\section{Alessandra Ximenes da SILVA***}

http://orcid.org/0000-0001-6362-2550

\begin{abstract}
Resumo: O artigo apresenta mediações entre os Direitos Humanos e a Política Nacional de Saúde Mental. Emerge de uma pesquisa que problematiza as ações ocorridas no governo de Michel Temer e as primeiras iniciativas do governo Bolsonaro ao promover um recrudescimento na área da saúde através de medidas neoliberais ortodoxas, reverberando na desestruturação da Rede de Atenção Psicossocial. O estudo realizou-se através de pesquisa documental com enfoque nas legislações pertinentes ao tema. Desse modo, as recentes mudanças resultam num retrocesso de 30 anos, quando predominava a barbárie no tratamento. Aquele governo e o atual traçaram estratégias neoconservadoras para violar os Direitos Humanos conquistados pela classe trabalhadora, a exemplo do retorno do uso dos hospitais psiquiátricos, representando um distanciamento de toda a luta antimanicomial.
\end{abstract}

Palavras-chave: Direitos Humanos. Saúde Mental. Neoconservadorismo.

Abstract: This article presents mediations between Human Rights and the National Mental Health Policy. It is based on research that emphasises actions during Michel Temer's government and the first initiatives of Bolsonaro's government in promoting a reopening of discussions on the area of health, following orthodox neoliberal attitudes, that have culminated in disruption to the Psychosocial Care Network. The study was carried out through documentary research focused on relevant legislation on the theme. The recent changes have resulted in a 30-year setback, a retrogression to a period when more barbaric treatments predominated. Both Temer's government and the incumbent one outlined neoconservative strategies to violate the hard-won Human Rights of the working classes, including the return to the use of psychiatric hospitals, which represents a departure from the whole anti-asylum struggle.

Keywords: Human rights. Mental health. Neoconservatism.

Submetido em: 30/3/2020. Revisado em: 29/6/2020. Aceito em: 3/8/2020.

\footnotetext{
* Assistente Social. Mestranda em Serviço Social pela Universidade Estadual da Paraíba. (UEPB, Campina Grande, Brasil). Rua Baraúnas, 351, Bairro Universitário, Campina Grande (PB), CEP 58.429500. E-mail: rosiane_oliverah@hotmail.com.

** Advogada. Mestranda em Serviço Social pela Universidade Estadual da Paraíba. (UEPB, Campina Grande, Brasil). Vieira Souto Advogados Associados. Rua Otacílio Nepomuceno, 100-A, salas 09/12, Bairro Catolé, Campina Grande (PB), CEP: 58410-160. E-mail: legaliteadv@yahoo.com.br.

${ }^{* * *}$ Assistente Social. Doutora em Serviço Social. Docente da Graduação e da Pós-Graduação em Serviço Social da Universidade Estadual da Paraíba. (UEPB, Campina Grande, Brasil). Rua Baraúnas, 351, Bairro Universitário, Campina Grande (PB), CEP: 58.429-500. E-mail: alesximenes@uol.com.br.
} copiar e redistribuir o material em qualquer suporte ou formato, bem como adaptar, transformar e criar a partir deste material para qualquer fim, mesmo que comercial. O licenciante não pode revogar estes direitos desde que você respeite os termos da licença.

Argum., Vitória, v. 12, n. 2, p. 75-90, maio/ago. 2020. | ISSN 2176-9575 


\section{Introdução}

$\mathrm{O}$ presente estudo objetiva analisar a desconsideração dos Direitos Humanos na Política Nacional de Saúde Mental brasileira. A problematização tem como recorte teórico temporal a Política Nacional de Saúde Mental (PNSM) sob a égide do governo Michel Temer (2016-2018) e as primeiras iniciativas do governo Jair Bolsonaro (2019-2020), cujas gestões intensificaram em demasia uma desestruturação das conquistas obtidas em décadas anteriores.

A discussão da problemática é fundamental, uma vez que as tendências da nova Política de Saúde Mental elaborada em 2017 foram o retorno do uso dos hospitais psiquiátricos na prestação de serviços direcionados às pessoas com transtornos mentais. Ressalta-se ainda a criação de uma rede de ambulatórios de saúde mental e de comunidades terapêuticas, cujos serviços já foram denunciados por não condizerem com os fundamentos basilares dos Direitos Humanos.

A relevância deste objeto cinge-se também à quantidade dos indivíduos com transtornos mentais, pois, em 2017, foram totalizados 30 milhões de brasileiros ${ }^{1}$ nessa situação, conforme a Organização Mundial da Saúde (DEPRESION..., 2017). São pessoas que sofrem restrições ao acesso universal da saúde pública - circunstância aviltante no campo dos Direitos Humanos.

Desse modo, a ocorrência do desmonte das políticas sociais em favorecimento à lógica mercadológica da saúde e o apoio à indústria farmacêutica e aos grupos empresariais desse campo têm restringido a assistência às demandas da classe trabalhadora através de um viés conservador.

Após este sucinto preâmbulo, a intenção das autoras deste trabalho consiste em refletir sobre a temática à luz da teoria crítica, utilizando a análise documental da Resolução no 32, de 14 de dezembro de 2017, da Resolução no 1/2018, e da Nota Técnica no 11/2019, que identificam os elementos necessários a respeito das mudanças realizadas na PNSM, no período do estudo. Para tanto, faz-se necessário retomar os subsídios expressos na Lei no $10.216 / 2001$, reverberando na defesa intransigente aos Direitos Humanos.

Nas seções seguintes, serão analisadas a dialeticidade dos Direitos Humanos na Saúde Mental; a Saúde Mental no contexto de recrudescimento do neoliberalismo ortodoxo durante o governo de Michel Temer; as prospecções reacionárias na Saúde Mental e Drogas na Era Bolsonaro; e as considerações finais.

\section{A dialeticidade dos Direitos Humanos na Saúde Mental}

Os Direitos Humanos são conceitualmente direitos caracterizados por serem ínsitos ao homem independentemente de qualquer outra condição, sendo garantias essenciais à construção de sua dignidade enquanto pessoa, ou seja, "[...] são aqueles inerentes ao homem enquanto condição para sua dignidade, e que usualmente são descritos em

\footnotetext{
${ }^{1}$ De acordo com a OMS (DEPRESSION..., 2017), houve um aumento no diagnóstico de transtornos mentais no Brasil.
}

Argum., Vitória, v. 12, n. 2, p. 75-90, maio/ago. 2020. | ISSN 2176-9575 
documentos internacionais para que sejam mais seguramente garantidos" (OLIVEIRA; LAZARI, 2018, p. 55).

Destaca-se ainda uma sutil diferença entre Direitos Humanos e Direitos Fundamentais. O traço distintivo é a origem do documento legislativo que lhes dá garantia: os Direitos Humanos têm natureza supranacional, passando a serem denominados Direitos Fundamentais quando são normatizados no plano interno de um país. Essa diferenciação ocorre em virtude do fato de que, na sua incorporação nacional, os Direitos Humanos são adaptados conforme as peculiaridades de cada nação, muito embora seja respeitada uma matriz genérica internacionalmente consagrada (OLIVEIRA; LAZARI, 2018).

O movimento de institucionalização dos Direitos Humanos é recente no Brasil e podese dizer que foi inaugurado pela Constituição Federal de 1988, que inclusive prevê no seu artigo 196: "[...] a saúde é direito de todos e dever do Estado" (BRASIL, 1988). Essa conquista também faz parte das lutas do movimento da Reforma Sanitária, que desde a década de 1970 defendia uma saúde pública e de qualidade para todos.

Somente a partir da Conferência de Viena em 1993, foi introduzida a construção da Agenda Brasileira de Direitos Humanos. Esse processo foi considerado demorado devido à questão da Ditadura Militar, que dizimou e encarcerou centenas de vidas nos duros e longos 21 anos em que vigorou. Vale a pena ressaltar que o tema da violação dos Direitos Humanos foi um dos pontos mais importantes da agenda política no período de transição para a democracia em diversos países da América Latina (FREIRE, 2013).

No entanto, apesar dessa morosidade, dado o caráter de universalidade dos Direitos Humanos, resta claro que o direito à saúde está incorporado ao seu conceito, em virtude do dever governamental de prestar serviços de saúde a todo ser humano. Especificamente em relação ao direito à saúde, este é o gênero normativo no qual a saúde mental está incluída, estando intrinsecamente correlacionada aos Direitos Humanos. Nesse sentido, dentre os principais direitos e compromissos previstos no Pacto Internacional de Direitos Econômicos, Sociais e Culturais, cuja norma foi ratificada por nosso país, está previsto que: “[...] Artigo 12. 1. Os Estados-partes no presente Pacto reconhecem o direito de toda pessoa de desfrutar o mais elevado nível de saúde física e mental" (BRASIL, 1992).

No aspecto latino-americano, a primeira iniciativa no campo do direito à saúde e saúde mental foi a Declaração de Caracas em 1990, através da qual é assumido o compromisso de respeito aos Direitos Humanos dos sujeitos com transtornos mentais. Quase que concomitantemente, em nosso país houve a criação do Sistema Único de Saúde (SUS), regulamentado pela Lei de $\mathrm{n}^{\circ} 8.080 / 1990$ e posteriormente complementado pela Lei $\mathrm{n}^{\mathbf{0}}$ 8.142/1990, com base na concepção de seguridade social (firmada no tripé saúde, previdência e assistência social).

Em 2001, após quase 12 anos de tramitação no Congresso brasileiro, foi instituída a Lei no 10.216/2001 (BRASIL, 2001) para regulamentar a Política Nacional de Saúde Mental no Brasil baseada em aspectos da Reforma Psiquiátrica. A partir desse marco legal, houve o

Argum., Vitória, v. 12, n. 2, p. 75-90, maio/ago. 2020. | ISSN 2176-9575 
redirecionamento do modelo de assistência aos sujeitos com transtornos mentais com a criação da Rede de Atenção Psicossocial (RAPS) e o uso de novas formas de tratamento em rede de serviços substitutivos aos hospitais psiquiátricos. Desde a vigência de tal norma, houve uma quebra do paradigma, segundo o qual "[...] o portador de transtorno mental era visto como objeto e não como sujeito de direito" (MARCHEWKA; PITTA; DINIZ, 2008, p. 187).

Na América do Sul, especificamente no denominado Cone Sul (Brasil, Chile, Uruguai e Argentina), o Brasil se destaca no âmbito da saúde mental em relação aos outros países por ter sido o pioneiro na construção da Política de Saúde Mental, pois há nações que não possuem sequer uma legislação específica sobre a temática, a exemplo do Chile, onde inexiste uma norma universal que garanta a assistência ao tratamento daqueles que sofrem transtornos mentais - a legislação chilena tem escasso acervo de normas que versem sobre a saúde mental (HERNANDO, 2016).

As outras nações do Cone Sul - Uruguai (2017) ${ }^{2}$ e Argentina (2010) 3 - apresentam suas leis específicas para a área da saúde mental, sendo semelhantes na defesa baseada nos Direitos Humanos, ao assegurar o direito à proteção e tratamento para as pessoas com transtornos mentais, reconhecendo o Estado como garantidor do desenvolvimento da Política de Saúde Mental.

E apesar de o Brasil ter se destacado no pioneirismo de legislação sobre saúde mental, nos últimos anos, vem sofrendo uma ofensiva demasiada nesse campo, principalmente devido ao recrudescimento do neoliberalismo puro sangue (PAULANI, 2016) e à representação do neoconservadorismo com todo o vigor. As ações do governo de Michel Temer para desestruturação da RAPS contrariaram o que vinha sendo construído pelo movimento da Reforma Psiquiátrica.

Portanto, em atendimento aos pressupostos neoconservadores do capital financeiro, o contexto de contrarreformas do Estado implica no desmonte dos Direitos Humanos que alicerçam a Política de Saúde Mental, impondo desafios na contemporaneidade à efetiva operacionalização dos respectivos serviços, sendo tal conjuntura abordada a seguir.

\section{A saúde mental no contexto de recrudescimento do neoliberalismo ortodoxo: um mix de passado e presente}

A atual conjuntura é complexa e apresenta um momento político difícil, numa correlação de forças que desfavorece as conquistas da classe trabalhadora diante da investida imperialista do capital, representando grande retrocesso no campo das políticas sociais, principalmente na saúde. Por conseguinte, os traços conservadores são pertinentes ao contexto de contrarreformas e fundamentados numa racionalidade que instrumentaliza e naturaliza as relações sociais, de modo que ela esteja mesclada entre o novo e velho (COSTA, 2016).

${ }^{2}$ No Uruguai, a temática é tratada na Lei no ${ }^{0}$ 19.529/2017.

3 Na Argentina, a temática é tratada na Lei no ${ }^{\circ} 26.657 / 2010$.

Argum., Vitória, v. 12, n. 2, p. 75-90, maio/ago. 2020. | ISSN 2176-9575 
Portanto, é justamente no contexto de recrudescimento do neoliberalismo ortodoxo, materializado no governo ilegítimo de Michel Temer (2016-2018), que se presencia a reatualização do conservadorismo - neoconservadorismo (BARROCO, 2015).

O governo de Temer inegavelmente representou os setores mais reacionários, retrógrados e conservadores da sociedade brasileira, aliados à burguesia (TEIXEIRA, 2018). Trata-se de um "[...] projeto político ultra neoliberal [sic], assumidamente prócapital, que visa resolver os impasses de acumulação e favorecer os interesses da classe dominante do país e aprofundar sua dependência junto ao capital internacional" (BRAVO; PELAEZ; PINHEIRO, 2018, p. 12).

Esses elementos estão presentes nas ações governamentais realizadas no âmbito da saúde mental. A contrarreforma na Política Nacional de Saúde Mental (PNSM) naquele período se configurou como a maior ofensiva desde o movimento da Reforma Psiquiátrica, isso porque:

A reforma psiquiátrica tem sido a diretriz da política pública adotada paulatinamente, com avanços e recuos, pelo governo brasileiro desde a década de 1990, permanentemente sendo negociada entre as forças políticas. Contudo, a adoção da reforma psiquiátrica acontece num momento histórico e contraditório em que os países da América Latina começam a vivenciar os primeiros ensaios neoliberais. (DIAS, 2007, p. 134).

É com o recrudescimento do neoliberalismo ortodoxo a partir do Golpe de 2016 que acontecerá a desconfiguração da PNSM estruturada a partir da implementação da Resolução no 32/2017 e da Resolução no 1/2018, uma vez que colocarão novamente em centralidade os hospitais psiquiátricos e a ampliação do financiamento e legitimação das comunidades terapêuticas no rol dos serviços da RAPS para as pessoas com problemas decorrentes de um determinado padrão de relação com as drogas.

A Resolução no 32 foi aprovada no final de 2017 pelo gestor público federal responsável pela área, Dr. Quirino Cordeiro Júnior, em uma reunião da Comissão Intergestores Tripartite $(\mathrm{CIT})^{4}$ em Brasília, sem que houvesse qualquer debate com participação da sociedade. Logo, é patente o estado atual da democracia meramente formal em nosso país, pois há uma forte blindagem no espaço público, onde, ao contrário, deveria haver diálogo. Na época presente, vivencia-se "[...] uma nova forma de trato da velha 'questão social' por parte do Estado capitalista" (DEMIER, 2017, p. 33).

Nesse sentido, a nova revisão da PNSM foi aprovada nesses pressupostos de interesse da elite burguesa. Dentre as alterações, promoveram-se:

A Suspensão do fechamento de leitos em hospitais psiquiátricos e, ainda o aumento no valor pago pelo governo por diária de internação nesse tipo de serviço; os Hospitais Gerais poderão utilizar até $20 \%$ de sua capacidade para alas psiquiátricas, sendo que enfermarias com maior número de leitos terão incentivos maiores do que enfermarias com vagas reduzidas, devendo

\footnotetext{
4 Válido esclarecer que a Comissão Intergestores Tripartite é composta por representantes do Ministério da Saúde, do Conselho Nacional de Secretários de Saúde (Conass) e do Conselho Nacional de Secretarias Municipais de Saúde (Conasems).
} 
permanecer com 8o\% de ocupação; financiamento oficial do Ministério da Saúde às Comunidades Terapêuticas; novo modelo de Caps 24 horas para atendimento a usuários de álcool e outras drogas, entre outras alterações. (BORGES, 2017, não paginado).

As medidas tiveram apoio de algumas entidades, como a Associação Brasileira de Psiquiátrica (ABP) e o Conselho Federal de Medicina (CFM), que, historicamente, no Brasil, fizeram das instituições manicomiais verdadeiros campos de concentração com a promoção de uma espécie de holocausto brasileiro (BORGES, 2017).

Essa revisão foi repudiada por outras entidades, como destaca o Observatório de análise política em saúde (BOLETIM PROJETO ANÁLISE DE POLÍTICAS EM SAÚDE NO BRASIL (2013-2017), 2018, não paginado), entre elas: o Conselho Federal de Psicologia (CFP), o Conselho Federal de Serviço Social (CFESS), a Associação Brasileira de Saúde Coletiva (Abrasco), o Movimento Nacional de Luta Antimanicomial (MNLA) e a Associação Brasileira de Saúde Mental (Abrasme), que considerou a proposta como "antiética, ilegal e inconstitucional", apoiada, inclusive, pela indústria farmacêutica e pelo complexo empresarial hospitalar.

Pensar o acesso humanizado à saúde mental como a efetivação de um dos Direitos Humanos do usuário requer primeiramente romper com o histórico místico, depreciativo, repulsivo, coercitivo e excludente que imperou por longo tempo na sociedade brasileira, que negava o convívio com os portadores de enfermidades mentais, encarcerando-os de modo a reduzi-los a seres vivos, mas não inteiramente humanos (SANTOS et al., 2018). Logo, a nova revisão da PNSM revestida do velho quer aprimorar os laços com as raízes conservadoras da sociedade brasileira que tendem a reproduzir estratégias para dificultar ou negar as conquistas da classe trabalhadora (COSTA, 2019).

A proposta de mudança na Política de Saúde Mental, através da qual o governo pretendeu investir nos serviços e hospitais psiquiátricos, embora contemplasse a criação de vagas em hospitais gerais, representou a responsabilidade de execução para os setores privados do capital por meio da construção de novos hospitais e clínicas psiquiátricas com vistas à lucratividade e refilantropização de serviços. Essa ampliação dos serviços hospitalares psiquiátricos representa o retorno a um passado sombrio, cuja superação só foi alcançada após muita luta (CONSELHO FEDERAL DE SERVIÇO SOCIAL, 2017).

A propósito, a Resolução no 32/2017 disciplina em seu artigo 1o que, para fortalecer as diretrizes da Rede de Atenção Psicossocial (RAPS), os hospitais psiquiátricos especializados serão incluídos como dispositivos/componentes da rede.

Esse desiderato é reafirmado na Nota Técnica no 11/2019, na qual o Ministério da Saúde afirma que "[...] não considera mais Serviços como sendo substitutos de outros, não fomentando mais fechamento de unidades de qualquer natureza. A Rede deve ser harmônica e complementar" (BRASIL, 2019d, p. 3-4). Ou seja, o hospital psiquiátrico terá espaço e financiamento garantido dentro da RAPS. Ainda é mencionado que:

Quando se trata de oferta de tratamento efetivo aos pacientes com transtornos mentais, há que se buscar oferecer no SUS a disponibilização do melhor aparato terapêutico para a população. Como exemplo, há a Eletroconvulsoterapia (ECT), cujo aparelho passou a compor a lista do Sistema de Informação e 
Gerenciamento de Equipamentos e Materiais (SIGEM) do Fundo Nacional de Saúde, no item 11711 (BRASIL, 2019d, p. 6).

Isso representa um retrocesso para toda a luta do movimento pela Reforma Psiquiátrica, pois rompe com o processo de superação da lógica manicomial que vinha sendo construída em nosso país e nos leva ao contexto de 30 anos atrás.

Nesse contexto acima mencionado, não havia respeito à dignidade humana, conforme os princípios da igualdade, liberdade e fraternidade que vigoram no campo dos Direitos Humanos (SANTOS et al., 2018). No campo da saúde mental, o documentário Holocausto brasileiro fez um relato da desumanização do homem, ao abordar o Hospital Colônia de Barbacena, Minas Gerais, onde se estima que, ao longo de décadas, mais de 6o mil pessoas internadas morreram em estado deplorável. Essa película cinematográfica retratou o ano de 1979, oportunidade na qual Franco Basaglia, referência mundial na busca pela melhoria na qualidade da assistência prestada às pessoas com transtornos mentais, após visitar o Hospital Colônia de Barbacena, caracterizou aquele ambiente como um campo de concentração. Infelizmente, essa descrição pode se tornar realidade novamente na história brasileira.

Destarte, ainda em análise à Resolução no 32/2017, observa-se que ela apresenta contrariedade, uma vez que seu artigo $5^{\circ}$ veda "[...] qualquer ampliação da capacidade já instalada de leitos psiquiátricos em hospitais especializados [...]" (BRASIL, 2017); o artigo

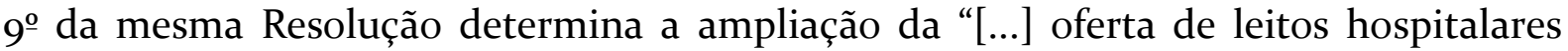
qualificados para a atenção a pessoas com transtornos mentais e/ou com necessidades decorrentes do uso de crack, álcool e outras drogas" (BRASIL, 2017). Contraria, desse modo, os pressupostos de luta em defesa da Reforma Psiquiátrica e o disposto na Lei no 10.216/2001 (BRASIL, 2001) e na Portaria GM/MS no 3.088/2011 (BRASIL, 2011).

Outro aspecto é a criação da Rede de Ambulatório de Saúde Mental, denominada de Assistência Multidisciplinar de Média Complexidade em Saúde Mental, uma espécie de serviço intermediário entre CAPS e Atenção Básica, sendo a novidade explicitada no artigo 6o da Resolução no 32/2017 (BRASIL, 2017). É possível compreender que a criação dessa rede de ambulatórios especializados em saúde mental apresenta-se como uma volta ao passado, uma vez que esses serviços existiam antes do processo da Reforma Psiquiátrica e foram suprimidos pela falta de resolutividade em seu funcionamento e por apresentar algumas irregularidades.

Desse modo, a perspectiva de quebrar a lógica de organização e estruturação dos serviços de saúde mental como estão articulados demonstra que o desígnio do governo de Michel Temer e as primeiras iniciativas do governo Bolsonaro são um retorno ao modelo de assistência de segregação e de desassistência dos usuários.

Isso porque o tratamento que visa à integralidade na saúde, e, especificamente, na saúde mental, tem como premissa reconhecer o protagonismo dos sujeitos envolvidos no processo de saúde-doença: usuários, gestores e trabalhadores. Estes devem compartilhar e, coletivamente, definir a estruturação dos serviços ofertados, buscando qualificar a oferta e asseverar a operação do direito e não visar sua retirada (SANTOS et al., 2018). 
Registra-se, igualmente, o artigo 11 dessa resolução quando menciona: "Fortalecer a parceria e o apoio intersetorial entre MS/MJ/MDS/MT em relação às Comunidades Terapêuticas" (BRASIL, 2017). Esse trecho legal é retrógrado na medida em que essas instituições já foram denunciadas por várias irregularidades, como violação aos Direitos Humanos. A maioria dessas comunidades está interligada a grupos religiosos com embasamentos morais e conservadores que se harmonizam com o ideário neoliberal (CONSELHO FEDERAL DE SERVIÇO SOCIAL, 2017).

A Resolução no 1/2018 aprovada pelo Conselho Nacional de Políticas sobre Drogas Conad, também defende fortalecer essas organizações e a estratégia da abstinência. Em seu artigo $1^{\circ}$, inciso III, destaca a “[...] ampliação e reorganização da rede de cuidados, [...] promoção da saúde, promoção da abstinência, suporte social e redução dos riscos sociais e à saúde e danos decorrentes" (BRASIL, 2018a, não paginado, grifos nossos).

Essa defesa da ampliação da rede com vistas à promoção da abstinência reforça a ideologia proibicionista hegemônica e dificulta as ações em torno da saúde coletiva com a estratégia da redução de danos, que, em sua visão mais humanitária e com direcionamento nos Direitos Humanos, não exclui a possibilidade de que o indivíduo queira ficar abstinente, mas dá para ele outras possibilidades para além da interrupção total do uso de drogas.

Em consonância com os retrocessos nesse campo, o parágrafo $2^{\circ}$ do artigo $\mathbf{1}^{\mathbf{0}}$ dessa resolução dispõe:

[...] A União deve promover de forma contínua o fomento à rede de suporte social, composta por organizações da sociedade civil e de prevenção, acolhimento, inclusive em comunidades terapêuticas [...] definindo parâmetros e protocolos técnicos com critérios objetivos para orientação das parcerias com a União (BRASIL, 2018a, grifos nossos).

A inserção das Comunidades Terapêuticas nos serviços de saúde contribui com a lógica neoliberal de minimizar as ações do Estado para a classe trabalhadora e maximizar sua função para o capital, uma vez que o desresponsabiliza pela execução da política e do repasse de recursos do fundo público ao capital privado, ocasionando efeitos em todos os setores da vida social dos sujeitos com problemas relacionados às substâncias psicoativas.

A inclusão dessas instituições na Rede de Atenção Psicossocial (RAPS) contraria os pressupostos e a luta da Reforma Psiquiátrica, uma vez que essas instituições não concretizam os ideais dos Direitos Humanos. Isso é compreendido no Relatório da Inspeção Nacional em Comunidades Terapêuticas, realizado pelo Conselho Federal de Psicologia (CFP) em conjunto com outras instituições.

Ao total, conforme CFP (2018), foram fiscalizadas 28 comunidades terapêuticas em todo o país no ano de 2017. A sistematização expõe a realidade concreta vivenciada nesses espaços de privação de liberdade, suas características e a complexidade de violações de direitos identificadas, que em síntese são: a existência de muros, trancas e restrições ao acesso a meios de comunicação; privação de liberdade; presença de castigos, punições e 
indícios de tortura, entre outras ilegalidades (CONSELHO FEDERAL DE PSICOLOGIA, 2018).

A relevância dos Direitos Humanos está centrada na proteção da vida do indivíduo, na compreensão de que as pessoas devem ser respeitadas e seus direitos assegurados, não podendo ser alvos de discriminação ou violência, por exemplo. Cabe ao Estado defender tais direitos em meio a uma sociedade democrática. Porém, diga-se de passagem, considerando o contexto histórico da saúde mental, ainda há muito a ser conquistado e defendido (SANTOS et al., 2018).

O governo deixou bem explícita sua intencionalidade quando aprovou a Portaria $\mathrm{n}^{\mathbf{o}}$ 3.659/2018 (BRASIL, 2018b), através da qual suspendeu o repasse dos recursos financeiros destinados aos serviços da RAPS, por ausência de registros de procedimentos nos sistemas de informação do SUS. Com a portaria, aproximadamente 322 serviços foram diretamente afetados por um corte de aproximadamente R $\$ 77,8$ milhões. Isso contraria a sua defesa de fortalecimento da RAPS, mencionada na Resolução no 32/2017 do Ministério da Saúde.

E em consonância com as ações de Michel Temer, o governo sucessor recrudesce suas intenções no que se referem ao âmbito da saúde mental, especialmente quanto aos usuários de drogas.

\section{As prospecções reacionárias na saúde mental e drogas na Era Bolsonaro}

Uma das primeiras medidas da gestão de Jair Messias Bolsonaro (2019) foi a promulgação do Decreto no 9.761/2019 (BRASIL, 2019a), que aprovou uma nova versão da Política Nacional sobre Drogas. A política reforça a lógica das comunidades terapêuticas e defende a abstinência como estratégia uniformizada no tratamento, dificultando alternativas que visem ao cuidado integral do sujeito e aos pressupostos dos Direitos Humanos, como é o caso da redução de danos defendida no âmbito da saúde coletiva.

A potência do posicionamento político da saúde pública de assumir a liderança da Política sobre Drogas com sua estratégia de redução de danos ainda está sob difícil e tensa construção, mas em conjuntura marcada por contradições a ser exploradas, conforme sinalizam Lima e Tavares (2012).

Em relação às incongruências no campo das substâncias psicoativas, ocorreu também a edição da Lei no 13.840/2019 (BRASIL, 2019C), que permite a internação involuntária para o tratamento feita não só pela família, como pelo responsável legal ou servidor da área da saúde. Logo, fica a lacuna para acontecer o encarceramento dos sujeitos que apresentam problemas decorrentes de um determinado padrão de relação com as drogas.

Conforme Brites (2013), a internação involuntária e a compulsória se caracterizam como canto de sereia, pois o canto das sereias é belo, irresistível e fatal, uma vez que leva quem o ouve a uma viagem sem volta ao fundo do mar. Metaforicamente, esses tipos de internação encarnam os atributos desse canto. Belo porque harmonioso em defesa da 
vida, da integridade e da solidariedade. Irresistível porque ecoa promessas imediatas e definitivas nos ouvidos cansados de ouvir lamentações de dor, perdas e violências. Entretanto, fatal porque anuncia o irrealizável e retrocede em conquistas.

A lógica da institucionalização de pessoas que fazem uso de álcool e outras drogas está inserida no mesmo vestígio histórico das pessoas com transtornos mentais. Sob a mesma justificativa do cuidado moral e ocupando o mesmo papel que a loucura ocupou historicamente (e ainda ocupa em nosso país), as pessoas com problemas decorrentes de determinado consumo de substâncias psicoativas são submetidas à privação de liberdade, também, sob o falso manto do cuidado (CONSELHO FEDERAL DE PSICOLOGIA, 2018).

As mudanças nas legislações são defendidas pelos seus idealizadores através de um suposto embasamento científico, porém essa defesa é questionável se considerarmos, por exemplo, que o estudo do III Levantamento Nacional sobre o Uso de Drogas pela população brasileira, realizado pela Fundação Oswaldo Cruz (Fiocruz) entre 2014-2017 (FUNDAÇÃO OSWALDO CRUZ; INSTITUTO DE COMUNICAÇÃO E INFORMAÇÃO CIENTÍFICA E TECNOLÓGICA EM SAÚDE, 2017), demonstrou que não há a tão famosa epidemia de drogas como é noticiada cotidianamente pelos espaços midiáticos, e a substância mais consumida não é o crack, como foi objeto para criação de tantos programas governamentais. Esse estudo foi censurado e recebeu diversas críticas do então governo Michel Temer devido aos resultados. Após um longo processo de diálogos, a pesquisa foi liberada para conhecimento da sociedade apenas em 2019.

Para beneficiar suas ações retrógradas no campo das substâncias psicoativas e fortalecer seu posicionamento conservador, o Ministério da Cidadania do governo Bolsonaro escolheu a dedo quem irá realizar dois estudos nacionais sobre o uso de drogas. Insatisfeito com o resultado da última pesquisa, vai repassar, sem edital de seleção, R\$ 11,9 milhões a um grupo de pesquisa - Unidade de Pesquisa em Álcool e Drogas (Uniad)5 - alinhado ao governo, como afirma Levy (2020).

A censura realizada contra o estudo representa a perspectiva adotada pelo governo da época de fortalecer ainda mais a guerra às drogas e a abstinência como única estratégia de tratamento. Como afirma Souza (2018, p. 199): "O paradigma da abstinência antes de operar a universalidade como um recurso em nome da vida, se aplica como uma verdade sobre a vida”. A mesma postura prevalece no atual governo.

Para o mencionado autor, a estratégia da abstinência como regime de visibilidade se sustenta em torno daqueles usuários de substâncias psicoativas que se tornaram contraproducentes ao modo de produção: os moradores de rua, viciados, dependentes, craqueiros e toda uma série de nomenclaturas para expressar uma pretensa universalização de um tipo específico e particular de usuário. Nesse sentido, temos que

5 O diretor da Unidade de Pesquisa em Álcool e Drogas (Uniad), é um conhecido defensor da internação compulsória, das comunidades terapêuticas e da existência de uma epidemia de drogas: Ronaldo Laranjeira, psiquiatra e dono de uma clínica para recuperação de "casos complexos em dependência química". Ele passou os últimos anos coordenando o Recomeço, programa do governo estadual de São Paulo dedicado ao tratamento de usuários de drogas (LEVY, 2020). 
a "[...] abstinência como meta, dependente químico como diagnóstico e internação compulsória como medida são acionados como um círculo vicioso que individualiza o fracasso e ao mesmo tempo possibilita uma intervenção de corte populacional" (SOUZA, 2018, p. 104).

Em sequência dos atos governamentais contrários aos Direitos Humanos, é aprovado o Decreto no 9.926/2019 (BRASIL, 2019b), através do qual a sociedade civil foi retirada do Conselho Nacional de Políticas sobre Drogas (Conad), assim como os Conselhos Profissionais. Dessa forma, o referido Conselho passou a ser composto, majoritariamente, por integrantes governamentais. Para Noelle (2019), essa atitude reforça uma perspectiva focada não mais no cuidado às pessoas, mas na criminalização e repressão ao uso das substâncias psicoativas, atendendo aos pressupostos do proibicionismo.

Tem-se, assim, que o modelo preconizado nesse governo é de cunho repressivo ao promover severas violações aos Direitos Humanos dos sujeitos com transtornos mentais e usuários de substâncias psicoativas no Brasil, que carecem de uma política pública de qualidade. Logo, os projetos nesse campo estão sendo subsidiados com vistas à expansão lucrativa dos capitalistas, cujos interesses são voltados a uma ideologia conservadora punitivista, principalmente ao propagar uma cultura de violência institucional nos complexos hospitalares.

Brites (2013) destaca que o uso das drogas e a violência associada ao narcotráfico são, na maioria das situações acolhidas nos Serviços de Saúde e de Assistência Social, apenas parte das necessidades apresentadas pelos usuários e seus familiares, uma vez que a realidade dessas pessoas muitas vezes é determinada por trajetórias marcadas pelo abandono, desproteção e violação de direitos, que envolvem precárias condições ou ausência de moradia, renda, educação e saúde, dentre outras necessidades de reprodução social.

Nesse sentido, a ausência de respostas por parte do Estado brasileiro às diferentes e complexas questões articuladas às substâncias psicoativas não pode mais ser tolerada, (ACSELRAD, 2005). O modelo que vem sendo preconizado é de cunho repressivo ao promover severas violações aos Direitos Humanos das pessoas no Brasil que carecem de políticas públicas de qualidade.

\section{Considerações finais}

As violações dos Direitos Humanos rebatem diretamente nas demandas, condições e viabilidade da política nacional de saúde mental. Apesar da característica supranacional de tais direitos, nota-se que sua aplicabilidade é modificada de acordo com o país que incorpora a legislação internacional, sendo possível aferir que o cenário latinoamericano apresenta-se como de vanguarda no campo legislativo, à exceção do Chile. Porém existe um hiato na efetividade de tais normas.

No caso brasileiro, o contexto é preocupante, uma vez que as medidas adotadas pelos governos de Michel Temer e de Jair Bolsonaro contrariaram os pressupostos da luta pela 
Reforma Psiquiátrica e se assemelham à estrutura das raízes conservadoras que revestem o velho como algo novo. O retorno dos hospitais psiquiátricos, o fortalecimento da abstinência com ênfase no proibicionismo, a internação involuntária como meio de encarceramento dos indivíduos e a inclusão oficial das comunidades terapêuticas na RAPS significam um retorno ao passado sombrio e de desassistência aos sujeitos com transtornos mentais e àqueles com problemas decorrentes de um determinado padrão de relação com as drogas.

Desse modo, a perspectiva para a PNSM frente ao novo governo é de assiduidade às contrarreformas que estavam sendo realizadas, contudo, expõe um caráter ainda mais conservador devido ao perfil neofascista desta atual gestão. Logo, a presente conjuntura requer a resistência, a defesa dos Direitos Humanos e o fortalecimento da luta antimanicomial e antiproibicionista em nosso país.

\section{Referências}

ACSELRAD, Gilberta. A educação para a autonomia: construindo um discurso democrático sobre as drogas. In: ACSELRAD, Gilberta (Org.). Avessos do prazer: drogas, Aids e direitos humanos [online]. Rio de Janeiro: Editora Fiocruz, 2005.

ARGENTINA. Poder Legislativo. Ley 26.657 de 2010. Derecho a la Protección de la Salud Mental. Disposiciones complementarias. Derógase la Ley № 22.914. Buenos Aires, 2020. Disponível em:

http://servicios.infoleg.gob.ar/infolegInternet/anexos/175000179999/175977/norma.htm. Acesso em: 22 ago. 2019.

BARROCO, Maria Lúcia Silva. Não passarão! Ofensiva neoconservadora e Serviço Social. Revista Serviço Social \& Sociedade, São Paulo, n. 124, p. 623-636, 2015.

BOLETIM PROJETO ANÁLISE DE POLÍTICAS EM SAÚDE NO BRASIL (2013-2017). Salvador: Observatório de Análise Política em Saúde; Centro de Documentação de Análise Política em Saúde, ano 4, n. 15, jan./fev. 2018. Disponível em: https://www.analisepoliticaemsaude.org/oaps/boletim/edicao/15/. Acesso em: 13 ago. 2019.

BORGES, Domênica. Ministério da Saúde aprova retrocessos na Política Nacional de Saúde Mental. [S. 1.]. Esquerda Diário, 2017. Disponível em: http://www.esquerdadiario.com.br/Ministerio-da-Saude-aprova-retrocessos-naPolitica-Nacional-de-Saude-Mental. Acesso em: 24 ago. 2019.

BRASIL. [Constituição de 1988]. Constituição da República federativa do Brasil de 1988. Brasília (DF): Senado Federal, 1988. Disponível em: http://www.planalto.gov.br/ccivil_03/Constituicao/Constituiçao.htm. Acesso em: 12 ago. 2019.

BRASIL. Presidência da República. Decreto no 9.761, de 11 de abril de 2o19. Aprova a Política Nacional sobre Drogas. Brasília (DF), 2019a. Disponível em: 
http://www.planalto.gov.br/ccivil_03/_ato2019-2022/2019/decreto/D9761.htm. Acesso em: 15 maio 2020.

BRASIL. Presidência da República. Decreto no 9.926, de 19 de julho de 2019. Dispõe sobre o Conselho Nacional de Políticas sobre Drogas. Brasília (DF), 2019b. Disponível em: http://www.planalto.gov.br/ccivil_03/_Ato2019-2022/2019/Decreto/D9926.htm. Acesso em: 15 mai. 2020.

BRASIL. Presidência da República. Decreto no 591, de 6 de julho de 1992. Atos Internacionais. Pacto Internacional sobre Direitos Econômicos, Sociais e Culturais. Brasília (DF), 1992. Disponível em: http://www.planalto.gov.br/ccivil_03/decreto/19901994/do591.htm. Acesso em: 12 ago. 2019.

BRASIL. Lei no $\mathbf{1 3 . 8 4 0}$, de $\mathbf{5}$ de junho de 2019. Dispõe sobre o Sistema Nacional de Políticas Públicas sobre Drogas e as condições de atenção aos usuários ou dependentes de drogas e para tratar do financiamento das políticas sobre drogas. Brasília (DF), 2019c. Disponível em: http://www.planalto.gov.br/ccivil_03/_ato20192022/2019/lei/L13840.htm. Acesso em: 20 maio 2020.

BRASIL. Lei no 10.216, de 6 de abril de 2001. Dispõe sobre a proteção e os direitos das pessoas portadoras de transtornos mentais e redireciona o modelo assistencial em saúde mental. Brasília (DF), 2001. Disponível em:

http://www.planalto.gov.br/ccivil_03/leis/leis_2001/110216.htm. Acesso em: 20 fev. 2020.

BRASIL. Ministério da Justiça. Resolução no 1, de 9 de março de 2018. Define as diretrizes para o realinhamento e fortalecimento da PNAD - Política Nacional sobre Drogas. Brasília (DF), 2018a. Disponível em:

http://www.lex.com.br/legis_27624178_RESOLUCAO_N_1_DE_9_DE_MARCO_DE_201 8.aspx. Acesso em: 15 fev. 2020.

BRASIL. Ministério da Saúde. Resolução no 32, de 14 de dezembro de 2017. Estabelece as Diretrizes para o Fortalecimento da Rede de Atenção Psicossocial (RAPS). Brasília (DF), 2017. Disponível em:

http://portalarquivos2.saude.gov.br/images/pdf/2018/janeiro/o5/Resolu----o-CIT-n--32.pdf. Acesso em: 27 jan. 2019.

BRASIL. Ministério da Saúde.Portaria no 3.659, de 14 de novembro de 2018. Suspende o repasse do recurso financeiro destinado ao incentivo de custeio mensal de Centros de Atenção Psicossocial (CAPS), Serviços Residenciais Terapêuticos (SRT), Unidades de Acolhimento (UA) e de Leitos de Saúde Mental em Hospital Geral, integrantes da Rede de Atenção Psicossocial (RAPS), por ausência de registros de procedimentos nos sistemas de informação do SUS. Diário Oficial, 2018b. Disponível em: http://www.in.gov.br/materia/-

Lasset publisher/KujrwoTZC2Mb/content/id/50486628/do1-2018-11-16-portaria-n-3659-de-14-de-n. Acesso em: 27 jan. 2019. 
BRASIL. Ministério da Saúde. Nota Técnica no 11/2019 CGMAD/DAPES/SAS/MS. Esclarecimentos sobre as mudanças na Política Nacional de Saúde Mental e nas Diretrizes da Política Nacional sobre Drogas. Brasília (DF), 2019d. Disponível em: http://pbpd.org.br/wp-content/uploads/2019/o2/o656ad6e.pdf. Acesso em: 12 ago. 2019.

BRASIL. Ministério da Saúde. Portaria/GM no 3088, de 23 de dezembro de 2011. Institui a Rede de Atenção Psicossocial para pessoas com sofrimento ou transtorno mental e com necessidades decorrentes do uso de crack e outras drogas, no âmbito do Sistema Único de Saúde (SUS). Brasília (DF), 2011.

BRAVO, Maria Inês; PELAEZ, Elaine; PINHEIRO, Wladimir. As contrarreformas na política de saúde do governo Temer. Argumentum, Vitória, v. 10, n.1, p.9-23, 2018. Doi 10.18315/argumentum.vioi1.19139. Disponível em:

https://periodicos.ufes.br/argumentum/article/view/19139. Acesso em: 18 ago. 2020.

BRITES. Cristina Maria. Internação compulsória: um canto de sereias. Revista Inscrita, Rio de Janeiro, v. 10, n. 14, p. 48-55, 2013.

CONSELHO FEDERAL DE PSICOLOGIA (CFP). Relatório da Inspeção Nacional em Comunidades Terapêuticas - 2017. Brasília (DF), 2018. Disponível em https://site.cfp.org.br/wp-content/uploads/2018/o6/Relatório-da-Inspeção-Nacionalem-Comunidades-Terapêuticas.pdf. Acesso em: 13 ago. 2018.

CONSELHO FEDERAL DE SERVIÇO SOCIAL (CFESS). Mudanças na Política Nacional de Saúde Mental: mais uma ameaça do governo ilegítimo. Brasília (DF), 2017. Disponível em http://www.cfess.org.br/visualizar/noticia/cod/1439. Acesso em: 13 ago. 2018.

COSTA, Tereza Cristina Ribeiro da. A política de saúde mental na atualidade e o avanço do conservadorismo. Argumentum, Vitória, v. 11, n. 2, p. 163-178, maio/ago. 2019. Doi 10.18315/argumentum.v11i2.20848. Disponível em: https://periodicos.ufes.br/argumentum/article/view/20848. Acesso em: 18 ago. 2020.

COSTA, Tereza Cristina Ribeiro da. A política de saúde mental na contemporaneidade: entre a inovação e o conservadorismo. 2016. Tese (Doutorado em Serviço Social) - Universidade Federal de Pernambuco, Recife, 2016.

DEMIER, Felipe. Depois do golpe: a dialética da democracia blindada no Brasil. 1. ed. Rio de Janeiro: Mauad X, 2017.

DEPRESSION and Other Common Mental Disorders: Global Health Estimates. Geneva: World Health Organization; 2017. Disponível em: https://apps.who.int/iris/bitstream/handle/10665/254610/WHO-MSD-MER-2017.2eng.pdf;jsessionid=E6B5AoD309F451EDF5 ${ }_{5} \mathrm{~B}_{3}{ }_{3} \mathrm{~B}_{4} \mathrm{~B}_{557682 \mathrm{C}}$ ?sequence $=1$. Acesso em: 9 jul. 2020. 
DIAS, Miriam Thais Guterres. A Reforma Psiquiátrica brasileira e os direitos dos portadores de transtorno mental: uma análise a partir do serviço residencial terapêutico Morada São Pedro. 2007. 292 f. Tese (Doutorado em Serviço Social) Faculdade de Serviço Social, Pontifícia Universidade Católica do Rio Grande do Sul, Porto Alegre, 2007.

FREIRE, Silene de Moraes. Direitos Humanos no Brasil: ilusão jurídica ou possibilidade histórica? In: FORTI, Valéria; BRITES, Cristina (Org.). Direitos Humanos e Serviço Social: polêmicas, debates e embates. Rio de Janeiro: Lumen Juris, 2013. p. 150-170.

\section{FUNDAÇÃO OSWALDO CRUZ (FIOCRUZ); INSTITUTO DE COMUNICAÇÃO E INFORMAÇÃO CIENTÍFICA E TECNOLÓGICA EM SAÚDE (ICICT). III Levantamento Nacional sobre o uso de drogas pela população brasileira.} Organização: Francisco Inácio Pinkusfeld Monteiro Bastos et al. Rio de Janeiro, 2017. Disponível em: https://www.arca.fiocruz.br/handle/icict/34614. Acesso em: 22 ago. 2019.

HERNANDO, Marcela. Ley de Salud Mental para Chile. [S. 1.]. Elmostrador, 2016. Disponível em: https://www.elmostrador.cl/noticias/opinion/2016/o9/14/ley-de-saludmental-para-chile/. Acesso em: 23 ago. 2019.

HOLOCAUSTO BRASILEIRO. Produção de Daniela Arbex e Armando Mendz, baseada no livro homônimo de Daniela Arbex. Minas Gerais, 2016. 1 vídeo (1 h 49 min 49 s). Disponível em: https://www.youtube.com/watch?v=y6yxGzlXRVg. Acesso em: 21 fev. 2019.

LEVY, Clarissa. Ministério da Cidadania escolhe sem edital grupo aliado para fazer nova pesquisa sobre drogas. The Intercept, Rio de Janeiro, 9 mar. 2020. Disponível em https://theintercept.com/2020/o3/o9/ministerio-da-cidadaniapesquisa-sobre-drogas/. Acesso em: 10 maio 2020.

LIMA, Rita de Cassia Cavalcante; TAVARES, Priscilla. Desafios recentes às políticas sociais brasileiras sobre as drogas: enfrentamento ao crack e proibicionismo.

Argumentum, Vitória, v. 4, n .2, p. 6-23, jul./dez. 2012. Doi 10.18315/argumentum.v4i2.4659. Disponível em:

https://periodicos.ufes.br/argumentum/article/view/4659. Acesso em: 18 ago. 2020.

MARCHEWKA, Tânia Maria Nava; PITTA, José Cássio do Nascimento; DINIZ; Denise Pará. Saúde mental e direitos humanos. In: SCHOR, Nestor; DINIZ, Denise Pará (Org.). Guia de qualidade de vida: princípios, focos de estudo e intervenções. Barueri: Manole, 2008, p. 179-196.

NOELLE, Midiã. Programa Corra Pro Abraço é resistência nordestina. Justificando, 4 nov. 2019. Disponível em: http://www.justificando.com/2019/11/o4/programa-corrapro-abraco-e-resistencia-nordestina/. Acesso em: 15 dez. 2019. 
OLIVEIRA, Bruna Pinotti Garcia; LAZARI, Rafael de. Manual de Direitos Humanos: volume único. 4. ed. Salvador: JusPodivm, 2018.

PAULANI, Leda Maria. Uma ponte para o abismo. In: JINKINGS, Ivana; DORIA, Kim; CLETO, Murilo (Org.). Por que gritamos golpe?: Para entender o impeachment e a crise política no Brasil. São Paulo: Boitempo, 2016. p. 69-76.

SANTOS, Aline Brauna dos et al. Saúde mental, humanização e direitos humanos. Cadernos Brasileiros de Saúde Mental, Florianópolis, v. 10, n. 25, p. 1-19, 2018.

SOUZA, Tadeu de Paula. Estado e sujeito: a saúde entre a micro e a macropolítica... de drogas. 1. ed. São Paulo: Hucitec, 2018.

TEIXEIRA, Mary Jane de Oliveira. A urgência do debate: as contrarreformas na política da saúde mental no governo Temer. Argumentum, Vitória, v. 10, n. 1, p. 33-50, jan./abr., 2018. Doi 10.18315/argumentum.v10i1.19495. Disponível em: https://periodicos.ufes.br/argumentum/article/view/19495. Acesso em: 13 ago. 2019.

URUGUAI. Poder Legislativo. Ley no 19.529 de 2017. Salud mental. 2017. Disponível em: https://legislativo.parlamento.gub.uy/temporales/docu348498874864.htm. Acesso em: 22 ago. 2019.

Rosiane Oliveira da COSTA Trabalhou na concepção e delineamento do artigo, pesquisa documental e bibliográfica, análise e interpretação dos dados, redação e revisão crítica do artigo.

Assistente Social. Mestranda em Serviço Social pela Universidade Estadual da Paraíba (UEPB). Membro do Núcleo de Pesquisa em Política de Saúde e Serviço Social (Nupepss).

Nívea Maria Santos Souto MAIOR Trabalhou na concepção e delineamento do artigo, pesquisa documental e bibliográfica, análise e interpretação dos dados, redação e revisão crítica do artigo. Advogada. Mestranda em Serviço Social pela Universidade Estadual da Paraíba (UEPB). Mestranda em Direito pela Universidade Estácio de Sá (RJ). Especialista em Direito do Trabalho pela Universidade Cândido Mendes (RJ). Especialista em Meios Adequados de Solução de Conflitos (ESMA/UEPB). Membro do Grupo de Estudos e Pesquisas sobre Trabalho e Proteção Social (Getraps).

Alessandra Ximenes da SILVA Trabalhou na concepção e delineamento do artigo, pesquisa documental e bibliográfica, análise e interpretação dos dados, redação e revisão crítica do artigo.

Assistente Social. Doutora em Serviço Social pela Universidade Federal de Pernambuco (UFPE). Docente da Graduação e da Pós-graduação em Serviço Social, do Departamento de Serviço Social, da Universidade Estadual da Paraíba (UEPB). Líder do Núcleo de Pesquisa em Política de Saúde e Serviço Social (Nupepss). Coordenadora da pesquisa Contrarreforma e Aparelhos Privados de Hegemonia: as inflexões na política de saúde. Integrante do Fórum Paraibano em Defesa do SUS e contra a Privatização da Saúde e da Frente Nacional contra a Privatização da Saúde.

Argum., Vitória, v. 12, n. 2, p. 75-90, maio/ago. 2020. | ISSN 2176-9575 